\title{
PENERAPAN METODE PEMBELAJARAN BKPBI (BINA KOMUNIKASI PERSEPSI BUNYI DAN IRAMA) UNTUK ANAK YANG BERKEBUTUHAN KHUSUS (TUNARUNGU) DI SLB BINA SIWI BANTUL YOGYAKARTA
}

\author{
Khalilurrahman (08422001) dan M. Afdhal (09320163)
}

Jurusan Pendidikan Agama Islam FIAI Universitas Islam Indonesia

\begin{abstract}
Good communication in the education of children with special needs, is indispensable. This applies to all types of disorders. Communication is an important role within the individual in particular and in human life in general. Where a number of needs can only be conveyed through communication. So it is with children with special needs with all the shortcomings and obstacles. To meet the communication needs, the teacher should communicate the ability to develop optimally. Highly effective teaching materials that help children with special needs in this regard that deaf children with deaf children BKPBI material would be very easy to optimize residual hearing.
\end{abstract}

Keywords: communication, children with special needs, and BKPBI (Bina Komunikasi Persepsi Bunyi Irama).

\section{A. Latar Belakang Masalah}

Komunikasi yang baik dalam pendidikan anak berkebutuhan khusus sangat diperlukan. Hal ini berlaku untuk semua jenis kelainan. Komunikasi memang memegang peranan penting dalam diri individu khususnya dan dalam hidup manusia pada umumnya. Di mana sejumlah kebutuhan hanya dapat disampaikan lewat komunikasi. Demikian halnya dengan anak berkebutuhan khusus dengan segala keku- rangan dan hambatannya. Untuk memenuhi kebutuhan komunikasi, guru berupaya agar kemampuan berkomunikasi dapat berkembang secara optimal.

Salah satu anak berkebutuhan khusus yang mengalami hambatan komunikasi adalah anak tunarungu. Anak tunarungu dengan keterbatasan pendengaran, sebagai akibat dari hilangannya pendengaran mengalami hambatan perkembangan kemampuan 
dalam berkomunikasi secara lisan, sehingga menghambat pula pada proses kegiatan belajar yang merupakan bagian terpenting dalam pendidikan. Untuk itu, diperlukan peningkatan kualitas berkomunikasi. Salah satu upaya dalam meningkatkan kualitas berkomunikasi melalui optimalisasi sisa pendengaran, baik menggunakan alat bantu mendengar (ABM) atau tanpa alat bantu mendengar. Untuk memenuhi hal tersebut, seorang guru dituntut untuk dapat mencari alternatif pemecahan dan upaya-upaya dalam mengoptimalkan sisa pendengaran anak tunarungu. Beberapa kejadian inilah yang terjadi di SLB Bina Siwi Bantul Yogyakarta dan perlu dicarikan pemecahan masalahnya.

Oleh karena itu, dari pemaparan diatas peneliti ingin menyampaikan bahwa Penerapan Metode pembelajaran BKPBI (Bina Komunikasi Persepsi Bunyi dan Irama) untuk anak yang berkebutuhan khusus (tunarungu) di SLB Bina Siwi Bantul Yogyakarta sebagai salah satu alternatif sangat cocok untuk mengantisipasi hambatan komunikasi yang dialami sehingga penelitian ini menjadi penting untuk dilakukan dan diaplikasikan.

\section{B. Perumusan Masalah}

Adapun rumusan masalah yang ditemukan dari pemaparan dia atas adalah sebagai berikut:

1.Banyaknya Siswa Tunarungu di SLB

Bina Siwi Bantul yang memiliki hambatan berkomunikasi dalam PBM. Keadaan ini menyebabkan metode BKPBI penting untuk diterapkan agar mempermudah PBM.

2. Materi ajar untuk siswa Normal secara Normatif Kurang efektif jika diterapkan untuk anak tunarungu karena tidak sesuai dengan kebutuhan mereka.

\section{Tujuan Program}

Adapun tujuan dari penelitian ini adalah sebagai berikut:

1 Mempersiapkan para anak tunarungu SLB Bina Siwi Bantul untuk memasuki dunia kerja yang penuh dengan persaingan sehingga para anak tunarungu SLB Bina Siwi Bantul diharapkan dapat mengikuti program pelatihan ini dengan sungguh-sungguh dan penuh perhatian. Memberikan bekal kepada para anak tunarungu SLB Bina Siwi Bantul agar dapat hidup bermasyarakat dengan baik.

2. Mengarahkan para anak tunarungu SLB Bina Siwi Bantul agar menjadi pelopor dalam menyosialisasikan program BKPBI sehingga dapat memperlancar penguasaan berkomunikasi secara efektif

\section{Luaran yang Diharapkan}

Program Pelatihan ini akan menerapkan sebuah metode yang disebut BKPBI dari narasumber Hermanto, SP, M.Pd sebagai salah satu pakar psikologi anak berkebutuhan khusus. Metode 
yang diterapkan diharapkan dapat menjadikan para anak tunarungu mampu berkomunikasi secara efektif.

Dengan program pelatihan BKPBI ini, para siswa tunarungu di SLB Bina Siwi Bantul diharapkan menjadi anak yang handal serta mempunyai kemampuan berkomunikasi yang baik. Selanjutnya, mereka diharapkan dapat mempengaruhi dan mengajak para anak tunarungu yang lain dalam menumbuhkan kesadaran akan pentingnya kemampuan berkomunikasi yang efektif.

\section{E. Kegunaan Program}

Program pelatihan $\mathrm{BKPBI}$ ini diharapkan dapat berguna :

\section{Bagi mahasiswa}

a. Mengembangkan disiplin ilmu yang telah dipelajari, khususnya ilmu sosial dan psikologi anak luar biasa.

b. Meningkatkan kemampuan berpikir dan kepekaan diri dalam berbagai masalah pendidikan.

c. Melatih diri agar terbiasa berinteraksi dengan masyarakat.

e. Menunjukkan eksestensi mahasiswa yang peduli terhadap lingkungan sekitarnya.

\section{Bagi Masyarakat}

a.Meningkatkan kecerdasan dan mempermudah pembelajaran anak tunarungu sebagai salah satu elemen masyarakat.

b.Meningkatkan tingkat wawasan pendidikan di kalangan masyarakat
c.Memberikan sosialisasi kepada guru akan pentingnya metode ini sebagai bentuk pengabdian kepada masyarakat

\section{G. Gambaran Umum Masyarakat Sasaran}

\section{G.1 Analisis Lingkungan Opera- sional Sekolah \\ 1. Geografis}

a. Kondisi geografis di wilayah sekitar sekolah

Program penerapan metode pembelajaran $\mathrm{BKPBI}$ ini akan dilaksanakan di SLB Bina Siwi Bantul Yogyakarta. Sekolah ini terletak di wilayah jalan raya kecamatan Pajangan, Kabupaten Bantul. Dari jalan raya kurang lebih berjarak 50 meter. Udaranya cukup sejuk, tanah berpasir, dan padas sumber air dalam dan jernih. Akses jalan menuju sekolah ini sudah corblok mulai dari halaman sekolah sampai ke jalan raya.

b. Transportasi

Sekolah terletak di Jalan Pajangan Kabupaten Bantul dengan transportasiyang mudah ditempuh, baikdengan mobil maupun dengan sepeda motor.

\section{Demografi}

a. Jumlah anak berkebutuhan khusus Berdasarkan pendataan yang di lakukan oleh pihak SLB Bina Siwi pada tahun 2006 di Kecamatan Pajangan masih terdapat 20 orang 
anak berkebutuhan khusus yang belum bersekolah.

b. Tingkat pendidikan penduduk Tingkat pendidikan penduduk setempat berkisar antara SD sampai dengan $\mathbf{S 2}$.

\section{Ekonomi}

a. Penghasilan masyarakat sekitar pertahun rata-rata Rp5.400,00 (tergolong ekonomi lemah).

b. Pekerjaan masyarakat di sekitar SLB Bina Siwi antara lain sebagai petani, buruh bangunan, karyawan perusahaan, pedagang, pegawai negeri, dan pengusaha.

\section{Sosial Budaya}

a. Norma yang berlaku

Norma yang berlaku dalam di masyarakat sekitar SLB Bina Siwi cukup baik, ramah, toleransi dalam beragama, saling menghormati dan menghargai antar sesama, dan saling tolong menolong.

b. Adat istiadat

Adat istiadat masyarakat sekitar SLB Bina Siwi cukup baik, menjunjung tinggi sopan santun. Sebagian masyarakat masih menganut tradisi Jawa yang memiliki wawasan yang luas.

c. Seni budaya

Seni budaya masyarakat sekitar SLB Bina Siwi antara lain, shalawatan, seni musik, tari, reog, kuda lumping, wayang kulit, dan merti dusun (mejemukan).

\section{Keamanan}

Peran serta masyarakat dalam menjaga keamanan sekolah cukup signifikan. Bentuk kepedulian masyarakat sekitar terhadap keamanan SLB Bina Siwi ini antara lain lewat ronda malam, melaporkan peristiwa yang akan merugikan pihak SLB, dan ikut serta dalam pembangunan SLB Bina Siwi.

\section{G.2 Analisis Kondisi Pendidikan Sekolah saat ini}

SLB Bina Siwi pada saat ini telah memiliki standar isi kurikulum untuk jenjang SDLB, SMPLB, SMALB dan memiliki kurikulum 1994 tetapi belum selesai menyusun dan menerapkan Kurikulum Tingkat Satuan Pendidikan (KTSP).

Jumlah siswa seluruhnya pada saat ini berjumlah 43 orang anak. Sebagian besar siswa rata-rata telah berusia 7 tahun ke atas. Saat ini masih terdapat anak berkebutuhan khusus usia sekolah yang belum bersekolah (belum memperoleh layanan pendidikan) kurang lebih $45 \%$ guru yang dalam proses pembelajran yang menggunakan metode pakem dan CTL dan baru $7.5 \%$ siswa yang menghayati dan mengamalkan ajaran agama dalam kehidupan sehari-hari. Siswa yang memiliki prestasi akademik mengarang telah memperoleh juara II tingkat provinsi. Adapun untuk bidang-bidang lain hanya memiliki prestasi sampai tingkat kebupaten saja seperti, lari $100 \mathrm{M}$, meniti balok, dan cerdas cermat MIPA. 
Prestasi Akademik belum memenuhi standar nasional pendidikan (KKM rata-rata $65 \%$ ). Kelulusan ujian sekolah telah mencapai $100 \%$ dengan rata-rata nilai USEK 6,7. Jumlah tenaga kependidikan saat ini adalah 9 orang dengan perincian jenjang pendidikan sebagai berikut sarjana; S1: 1 orang, D3: 1 orang, D2 (SGPLB): 4 orang, SLTA: 2 orang, dan SMPLB: 1 orang;

Sarana dan Prasarana belum memenuhi standar minimal layanan pendidikan. Manejemen berbasis sekolah sudah berjalan tetapi belum maksimal dan $70 \%$ tupoksi pengelola sekolah sudah berfungsi sebagaimana mestinya. Komite sekolah sudah terbentuk, standar pembiayaan masih rendah karena kondisi ekonomi orang tua siswa masih lemah. Siswa tidak dipungut biaya pendidikan dan adapun sumber biaya pendidikan berasal dari bantuan pemerintah, bea siswa, dan dari para donator yang sifatnya tidak mengikat.

\section{H. Tinjauan Pustaka}

\section{H.1 Perkembangan Anak Tunarungu}

Di antara dampak utama ketunarunguan pada perkembangan anak adalah dalam bidang bahasa dan ujaran (speech). Kita perlu membedakan antara bahasa (sistem utama yang kita pergunakan untuk berkomunikasi) dan ujaran (bentuk komunikasi yang paling sering dipergunakan oleh orang yang dapat mendengar). Besar atau kecilnya hambatan perkem- bangan bahasa dan ujaran anak tunarungu tergantung pada karakteristik kehilangan pendengarannya. Hambatan tersebut dapat mengakibatkan kesulitan dalam belajar di sekolah dan dalam berkomunikasi dengan orang yang dapat mendengar/berbicara sehingga berdampak pada perkembangan sosial dan keragaman pengalamannya. Ini karena sebagian besar perkembangan sosial masyarakat didasarkan atas komunikasi lisan, begitu pula perkembangan komunikasi itu sendiri, sehingga gangguan dalam proses ini (seperti terjadinya gangguan pendengaran) akan menimbulkan masalah.

Telah dikemukakan di atas bahwa dalam banyak hal dampak yang paling serius dari ketunarunguan yang terjadi pada masa prabahasa terhadap perkembangan individu adalah dalam perkembangan bahasa lisan, dan akibatnya dalam kemampuannya untuk belajar secara normal di sekolah yang sebagian besar didasarkan atas pembicaraan guru, membaca, dan menulis. Seberapa besar masalah yang dihadapi dalam mengakses bahasa itu bervariasi dari individu ke individu. Ini tergantung pada parameter ketunarunguannya, lingkungan auditer, dan karakteristik pribadi masingmasing anak, tetapi ketunarunguan ringan pada umumnya menimbulkan lebih sedikit masalah daripada ketunarunguan berat. 


\section{a. Perkembangan Membaca}

Banyak penelitian yang dilakukan selama 30 tahun terakhir ini menunjukkan bahwa tingkat kemampuan membaca anak tunarungu berada beberapa tingkat di bawah anak sebaya/sekelasnya dan bahwa bahasa tulisnya sering mengandung sintaksis yang tidak baku dan kosakata yang terbatas

Terdapat bukti yang jelas bahwa berdasarkan tes. prestasi membaca yang baku, skor anak-anak tunarungu secara kelompok berada di bawah norma anak-anak yang dapat mendengar meskipun beberapa di antara mereka memperoleh skor normal untuk tingkat usia dan kelasnya.

Sejumlah penelitian telah dilakukan selama bertahun-tahun oleh Pusat Asesmen dan Studi Demografik di Gallaudet University di Washington DC. Diantaranya adalah penelitian yang dilakukan oleh Gentile (1973), yang mengetes lebih dari 16.000 siswa tunarungu dengan Stanford Achievement Test. Dia menemukan bahwa pada usia enam tahun skornya adalah ekuivalen dengan kelas 1,6, naik terus secara perlahan hingga menjadi ekuivalen dengan kelas 4,4 pada usia 19 tahun; kenaikan hanya sebesar 2,8 kelas selama 13 tahun. Temuan yang hampir sama dilaporkan di Inggris oleh Conrad (1979), yaitu bahwa mean (rata-rata) usia baca anak-anak tunarungu tamatan pendidikan dasar adalah 9 tahun 4 bulan; yang berkisar dari 10 tahun 4 bulan untuk tunarungu sedang hingga 8 tahun 3 bulan untuk tunarungu sangat berat. Data dari Australia juga-serupa. Ditemukan bahwa $66 \%$ dari sampel siswa tunarungu usia 11 tahun di negara-negara bagian Australia sebelah timur menunjukkan usia baca lebih dari 4 tahun di bawah usia kalendernya (Ashman \& Elkins, 1994). Di Selandia Baru, VandenBerg (1971) menemukan bahwa dari semua siswa SLB bagi tunarungu yang berusia hingga 14 tahun, tidak ada yang mencapai usia baca di atas 11 tahun. Data di atas tampak menunjukkan bahwa anak tunarungu mengalami kesulitan dalam membaca dan bahwa mereka semakin tertinggal oleh sebayanya yang dapat mendengar di kelas-kelas yang lebih tinggi di mana materi bacaan yang harus dibacanya semakin kompleks. Akan tetapi, Moores (1987) mengemukakan penjelasan lain untuk hasil penelitian tersebut. Sebagian besar penelitian itu dilakukan secara cross sectional, tidak mengikuti kemajuan siswa yang sama dan mengetesnya setiap tahun, sehingga mungkin bahwa tingkat kecacatan yang berbeda pada tahun yang berbeda akan mempengaruhi hasil tes itu, dan bahwa pemindahan siswa yang berkemampuan lebih tinggi ke sekolah reguler menyebabkan siswa ini tidak tercakup dalam survey sehingga hasil tes pada usia yang lebih tinggi skor rata-ratanya menurun. Satu penelitian oleh Allen (1986) mengatasi persoalan ini dengan melihat data dari hasil Stanford 
Achievement Test terhadap populasi tunarungu (kategori Hearing Impaired) pada tahun 1974 dan 1983. Skor tersedia dari usia 8 hingga 18 tahun, dan dia menemukan bahwa dari tahun 1974 hingga 1983 skor membaca sampel tunarungu itu meningkat setiap tahun. Walker dan Rickards (1992) di Victoria, Australia, juga telah memperoleh data yang menunjukkan bahwa anak tunarungu tertentu lebih baik hasilnya pada tes baku prestasi membaca daripada yang dilaporkan sebelumnya. Terus meningkatnya skor tes membaca anak tunarungu ini mungkin disebabkan oleh metode pengajaran membaca yang lebih baik. Argumen ini didukung oleh Ewoldt (1981) yang menemukan bahwa proses yang dipergunakan oleh anak tunarungu dalam membaca sama dengan yang dipergunakan oleh anak yang dapat mendengar, dan bahwa bila membaca mereka ditelaah menggunakan teknik yang tepat, ternyata mereka dapat lebih banyak memahami apa yang dibacanya.

\section{b. Bahasa tulis}

Dalam hal bahasa tulis, terdapat juga cukup banyak bukti bahwa anak tunarungu mengalami kesulitan untuk meñgekspresikan dirinya secara tertulis. Dalam beberapa penelitian yang berfokus pada ketepatan sintaksis bahasa Inggris tertulis anak tunarungu, ditemukan bahwa mereka cenderung menggunakan banyak frase yang sama secara berulang-ulang dalam kalimat sederhana, lebih sedikit kalimat majemuk, dan mereka membuat banyak kesalahan kecil dalam penggunaan tenses, kata bilangan, penggunaan kata ganti, kata penunjuk, dan lain-lain: Menjelang usia 12 tahun, mereka cenderung dapat menguasai penulisan kalimat-kalimat sederhana, tetapi bila mereka mencoba menulis kalimat yang lebih kompleks, kesalahan-kesalahan kecil muncul lagi. Akan tetapi, belum ada laporan hasil penelitian tentang tingkat keterbacaan tulisan anak tunarungu tetapi jika penyimpanganpenyimpangan dalam sintaksis diabaikan, bahasa tulis kebanyakan anak tunarungu dapat dimengerti dengan mudah, sehingga penggunaan bahasa tulisnya (yang sering merekka pergunakan untuk berinteraksi dengan orang yang dapat mendengar) biasanya dapat memungkinkan mereka berfungsi dengän cukup baik dalam kehidupan sehari-hari. Perlu juga diketahui bahwa terdapat sejumlah orang tunarungu, termasuk yang ketunarunguannya berat sekali, yang dapat mencapai tingkat kemampuan membaca dan menulis yang normal

\section{c. Ujaran (Speech)}

Banyak penélitian yang telah dilakukan tentang keterpahaman ujaran anak tunarungu pada berbagai tingkatan ketunarunguannya. Keterpahaman ujaran individu tunarungu bervariasi dari hampir normal hingga tak dapat dipahami sama sekali, 
kecuali oleh mereka yang mengenalnya dengan baik. Hasil penelitian yang terkenal adalah yang dilakukan oleh Hudgins dan Numbers (1942), yang menganalisis ujaran 192 anak tunarungu berat dan berat sekali. Mereka menemukan bahwa kekurangan dalam ujaran anak-anak ini adalah dalam hal ritme dan pemenggalan frasa, suaranya agak monoton dan tidak ekspresif, dan tidak dapat menghasilkan warna suara yang alami. Mereka juga menemukan bermacammacam kesalahan artikulasi pada bunyi-bunyi ujaran tertentu (kesalahan artikulasi vokal biasanya lebih sering daripada konsonan). Hudgins dan Numbers menemukan bahwa kurang dapat dipahaminya ujaran individu tunarungu itu lebih banyak diakibatkan oleh tidak normalnya ritme dan pemenggalan frasa daripada karena kesalahan artikulasi.

Terdapat tiga cara utama individu tunarungu mengakses bahasa, yaitu dengan membaca ujaran, dengan mendengarkan (bagi mereka yang masih memiliki sisa pendengaran yang fungsional), dan dengan komunikasi manual atau dengan kombinasi ketiga cara tersebut.

\section{H.2 Potret Anak Tunarungu Dalam Ilmu Psikologi}

Menurut beberapa pakar psikologi bahwa tiap-tiap anak memiliki tempo/ waktu dan irama perkembangan yang tidak sama. Ada anak yang memiliki tempo perkembangan cepat ada yang lambat. Ada anak yang tetap berjiwa anak, tetapi ada pula yang lekas berfikir dan bertindak seperti orang dewasa. Ada anak yang lancar proses perkembangannya pada masa kanak-kanak, ada juga yang lebih lancar pada masa remaja. Perkembangan seringkali bersifat menggelombang, bukan berjalan lurus. Pada suatu saat seseorang memiliki sifat tenang disaat berikutnya disusul sifat memberontak, goncang tapi akhirnya tenang lagi. Prinsip ini menyimpulkan bahwa anak yang memiliki umur kronologis yang sama tidak selalu mengalami taraf dan sifatsifat perkembangan yang sama.

Penderita tunarungu adalah mereka yang memiliki hambatan perkembangan indera mendengar. Tunarungu tidak dapat mendengar suara atau bunyi. Dikarenakan tidak mampu mendengar suara atau bunyi, kemampuan berbicaranyapun kadang menjadi terganggu. Sebagaimana kita ketahui, keterampilan berbicara seringkali ditentukan oleh seberapa sering seseorang mendengar orang lain berbicara., akibatnya anak-anak tunarungu sekaligus memiliki hambatan bicara dan menjadi bisu. Untuk berkomunikasi dengan orang lain, mereka menggunakan bahasa bibir atau bahasa isyarat. Sebagaimana anak tuna netra, mereka memiliki potensi perkembangan yang sama dengan anak-anak lain yang tidak mengalami hambatan perkembangan apapun. 


\section{H.3 Memahami Metode BKPBI Lebih Mendalam}

Program Khusus Bina Komunikasi Persepsi Bunyi dan Irama (BKPBI) adalah program khusus untuk pembinaan komunikasi dan pembinaan dalam penghayatan bunyi yang dilakukan dengan sengaja atau tidak, sehingga sisa pendengaran dan perasaan vibrasi (rasa getar) yang dimiliki anak dengan gangguan pendengaran (tunarungu) dapat dipergunakan sebaik-baiknya untuk berintegrasi dengan dunia di sekelilingnya yang penuh dengan bunyi. Ruang lingkup bahasan/program BKPBI terdiri dari dua dimensi yang sangat penting bagi anak tunarungu yaitu bina komunikasi dan bina persepsi bunyi dan irama. Bina komunikasi meliputi oral atau lisan, oralaural (dengan memanfaatkan sisa pendengarannya), oral campur isyarat, dan komunikasi total (oral,.aural, tulisan dan Sistem Isyarat Bahasa Indonesia atau disingkat SIBI. Bina persepsi bunyi dan irama berbentuk kegiatan melatih sisa pendengaran bagi anak tunarungu agar mampu menyadari adanya bunyi, membeda-bedakan bunyi, mengenali bunyi, dan memahami makna bunyi sehingga dapat memanfaatkannya dalam kehidupan sehari-hari.

\section{Metode Pelaksanaan Program}

Pelaksanaan Metode BKPBI ini tidak boleh terlepas dari pengajaran bahasa, maka latihan BKPBI musik selalu diakhiri dengan latihan BKPBI bahasa. Oleh karena itu pemilihan metode sebaiknya dikaitkan dengan metode yang dipergunakan dalam pengajaran bahasa. Metode yang dianjurkan dalam pelaksanaan $\mathrm{BKPBI}$ terutama percakapan, ditunjang berbagai metode yang relevan, yaitu metode permainan, demostrasi imitasi, pemberian tugas, dan metode observasi dengan cara mengamati respon anak terhadap rangsangan. bunyi. Adapun pendekatan metodenya antara lain: (a) Pendekatan multisensoris (visual, auditoria, taktil/pengalaman kontak)

Sedikit demi sedikit menuju pendekatan unisensoris atau peka-indra artinya hanya menggunakan indra pendengaran saja. (b) Pendekatan klasika! maupun individual. (c) Pendekatan BKPBI aktif, maksudnya siswa secara aktif menciptakan bunyi dan direspon sendiri, dan pendekatan pasif maksudnya siswa menyimak bunyi yang diproduksi oleh orang lain dan kemudian meresponnya. (d) Pendekatan formal artinya: direncanakan/diprogramkan. (e) Pendekatan tak formal artinya: tidak direncanakan jika terjadi bunyi secara tiba-tiba.

\section{Metode Pendekatan}

Metode BKPBI, yaitu: Permainan, b) Demonstrasi, c) Imitasi, d) Pemberian tugas, e) Observasi dengan cara mengamati respon anak terhadap rangsangan bunyi. Adapun pendekatan yang dilakukan yaitu melalui: 
a. Pendekatan multisensoris (visual, auditoris, taktil/pengalaman kontak) sedikit demi-sedikit menuju pendekatan unisensories atau peka indra, artinya hanya menggunakan indra pendengaran saja

b. Pendekatan klasikal maupun individual

c. Pendekatan BKPBI aktif, maksudnya siswa secara aktif menciptakan bunyi dan direspon sendiri, dan pendekatan pasif, maksudnya siswa menyimak bunyi yang diproduksi oleh orang lain dan kemudian meresponnya

d. Pendekatan formal artinya direncanakan /diprogramkan dan tidak formal, artinya tak direncanakan jika terjadi bunyi secara tiba-tiba

\section{J. Pelaksanaan Kegiataan}

Metode dilaksanakan dalam beberapa pertemuan:

\section{a. Pertemuan 1}

Pada pertemuan pertama ini TIM PKMM mengadakan pembukaan program BKPBI yang dibuka secara resmi oleh kepala SLB dan perkenalan program ini kepada para peserta dan kepada pihak SLB.

\section{b. Pertemuan II}

Pada pertemuan ke dua ini TIM PKMM memerkenalkan alat-alat permainan kepada para anak tunarungu yang akan digunakan untuk mempermudah jalannya program $B K P B I$ ini. Dan pada pertemuan ini pula TIM PKMM dan pemeteri mengadakan identifikasi pendengaran kepada para peserta program yang bertujuan untuk mengetahui sampai di mana kemampuan anak dalam pengoptimalisasian sisa pendengaran yang mereka miliki.

\section{c. Pertemuan III}

Di pertemuan yang ke tiga ini TIM PKMM dan pameteri merumuskan beberapa pendekatan program yang akan dilakukan untuk membantu peserta dalam mengoptimalisasikan sisa pendengaran mereka sesuai dengan hasil identifikasi bunyi yang telah dilakukan TIM pada pertemuan yang ke II.

\section{d. Pertemuan IV}

Pada pertemuan ke IV ini TIM dan pemateri akan mengimplementasikan pendekatan-penedekatan yang telah dirumuskan TIM dan pemeteri pada pertemuan yang ke III. Adapun pendekatan-pendekatan yang telah dirimușkan oleh TIM dan pemateri adalah:

Pendekatan multisensoris (visual, auditoris, taktil/pengalaman kontak) sedikit demi sedikit menuju pendekatan unisensories atau peka indra, artinya hanya menggunakan indra pendengaran saja

Pendekatan klasikal maupun individual

Pendekatan BKPBI aktif, maksudnya siswa secara aktif menciptakan bunyi dan direspon sendiri, dan 
pendekatan pasif, maksudnya siswa menyimak bunyi yang diproduksi oleh orang lain dan kemudian meresponnya.

Pendekatan formal artinya direncanakan/diprogramkan dan tidak formal, artinya tak direncanakan jika terjadi bunyi secara tiba-tiba

\section{e. Pertemuan V}

Pada pertemuan yang ke $\mathrm{V}$ ini TIM dan pemateri akan melanjutkan materi-materi dari pertemuan sebelumnya.

\section{f. Pertemuan VI}

Pada pertemuan yang ke VI ini TIM dan pemateri akan melanjutkan materi-materi dari pertemuan sebelumnya

\section{g. Pertemuan VII}

Pertemuan ini merupakan Evaluasi dan Pengulangan dari Materi yang telah diimplementasikan pada pertemuan-pertemuan sebelumnya

\section{h.Pertemuan VIII}

Di pertemuan yang terakhir ini akan di adakan monitoring dan sharing bersama antara TIM, Pemateri dan Pihak SLB. Pada pertemuan yang terakhir ini TIM mengadakan penutupan program $\mathrm{BKPBI}$ ini yang ditutup secara resmi oleh kepala SLB BINASIWI,BANTUL,YOGYAKARTA.

\section{K. Kesimpulan dan Saran}

\section{K.1. Kesimpulan}

Dari semua uraian yang telah dipaparkan di atas maka dapat diambil kesimpulan bahwa:
1).Komunikasi yang baik dalam pendidikan anak berkebutuhan khusus, sangat diperlukan. Hal ini berlaku untuk semua jenis kelainan. Komunikasi memang memegang peranan penting dalam diri individu khususnya dan dalam hidup manusia pada umumnya. Di mana sejumlah kebutuhan hanya dapat disampaikan lewat komunikasi. Demikian halnya dengan anak berkebutuhan khusus dengan segala kekurangan dan hambatannya. Untuk memenuhi kebutuhan komunikasi, guru berupaya agar kemampuan berkomunikasi dapat berkembang secara optimal.

2).Materi ajar yang efektif sangat membantu anak berkebutuhan khusus dalam hal ini anak-anak tunarungu yaitu dengan materi $\mathrm{BKPBI}$ anak tunarungu akan sangat mudah untuk mengoptimalisasikan sisa pendengarannya.

\section{K.2. Saran}

Saran yang dapat diberikan oleh penulis dari hasil penerapan program ini adalah:

1.Bagi masyarakat, agar lebih memperhatikan anak-anak yang berkebutuhan khusus.

2.Kepada orang tua, pendidik, agar dapat memberikan perhatian yang maksimal kepada anak-anak yang berkebutuhan khusus dalam pembahasan ini yaitu anak-anak tunarungu dan diharapkan bagi para 
pendidik anak-anak tunarungu untuk dapat membantu mereka dalam mengoptimalisasikan sisa - pendengaran yang mereka miliki.

3.Bagi akademisi, khususnya akademisi yang bergelut di dunia psikologi anak berkebutuhan khusus untuk lebih mengenal lebih dalam yaitu seperti, apa itu tunarungu, apa itu tunanetra, apa itu tuna grahita, Dan gejala-gejala yang melatar belakangi munculnya semua itu.

\section{Daftar Pustaka}

Agus, S. 2007. Berkomunikasi dengan Orang Tua [Online]. Tersedia: $h$ ttp:/ /gurukreatif.wordpress.com/2007/ 12/06/berkomunikasi-dengan-orang-tua. [20 Desember 2007].

Bunawan, L. dan Cecilia Susila Yuwati. 2000. Penguasaan Bahasa Anak Tunarungu. Jakarta: Yayasan Santi Rama.
Direktur Pembinaan Sekolah Luar Biasa. 2007. Standar Kompetensi dan Kompetensi DasarProgram Khusus Bina Persepsi Bunyi dan Irama $S D L B$ dan 5 MPLB Tunarungu. Jakarta: Direktorat Pembinaan 5LB Dirjen Manajemen Dikdasmen Depdiknas.

Melinda, E. 2008. "Pelatihan Program Khusus BPBI: Ruang Lingkup Materi Bina Persepsi Bunyi dan Irama". Makalah pada Diklat Pelatihan Guru BPBI BPG, Bandung. Moores, Danald F. 2001. Educating The Deaf Psychology, Principles, and Pretties, First Edition. New York: Houghton Mifflin Company.

Nugroho, B. 2002. Diktat Pelatihan Pemanfoatan Peralatan Audiometri, Bina Wicara, Bina Persepsi Bunyi dan Irama: Dasar-loser Bina Persepsi Bunyi dan Irama. Jakarta: Yayasan Pangudi Luhur. Sadja'ah, E. 2003. Bina Bicara 